\title{
Corrigendum to "Spatial controls on groundwater response dynamics in a snowmelt-dominated montane catchment" published in Hydrol. Earth Syst. Sci., 18, 1835-1856, 2014
}

\author{
R. S. Smith ${ }^{1}$, R. D. Moore ${ }^{2}$, M. Weiler ${ }^{3}$, and G. Jost ${ }^{4}$ \\ ${ }^{1}$ WaterSmith Research Inc., 450 Cadder Avenue, Kelowna, British Columbia, V1Y 5N3, Canada \\ ${ }^{2}$ Departments of Geography and Forest Resources Management, University of British Columbia, 1984 West Mall, \\ Vancouver, British Columbia, V6T 1Z2, Canada \\ ${ }^{3}$ Faculty of Environment and Natural Resources, University of Freiburg, Fahnenbergplatz, 79098 Freiburg, Germany \\ ${ }^{4}$ Generation Resource Management, BC Hydro, 6911 Southpoint Drive, 9th Floor Burnaby, \\ British Columbia, V3N 4X8, Canada
}

Correspondence to: R. S. Smith (rsmith@watersmith.ca)

We would like to inform you that the following reference is missing in the reference list of our above-mentioned paper.

\section{References}

Aquatic Informatics Inc.: Aquatic Informatics Inc. is the issuing organization, Vancouver, Canada, available at: www. aquaticinformatics.com, last access: 17 December 2012.

This reference is also missing in the acknowledgements. The updated acknowledgements should read as follows:

Acknowledgements. We would like to thank the following for assistance with the field study and logistical support: Dave Gluns, Pascal Szeftel, Michelle Sawka, Gerard Lohmann, Ryan Thoren, Nils Illchman, Natalie Stafl, Maria Staudinger, Fabian Nippgen, Nicolas Teichrob, Selina Agbayani, Kyle Terry, Roger Hodson, Stephanie Ewen, Vojtech Prilesky, Andres Varhola, Amy O’Neil, Jason Leach, Kim Green, Younes Alila, Diana Allen, Harry Verwoerd, Jerry Maedel, Vincent Kujala, Julie Ranada, and Nicholas Coops. Eric Leinburger provided cartographic assistance. Important funding and/or logistical support was provided by Tembec Inc., B. C. Ministry of Forests and Range, Forest Investment Account - Forest Sciences Program (grant nos. Y062294, Y081214), Kalesnikoff Lumber Co. Ltd., Alberta Pacific Forest Industries Inc., Natural Sciences and Engineering Research Council of Canada, Mathematics of Information Technology and Complex Systems Network of Centres of Excellence, Sustainable Forest Management Network, Aquatic Informatics
Inc., and the University of Zürich. Finally, we would like to thank Chris Spence, Jim McNamara, one anonymous reviewer, and the editor, Ross Woods, for their constructive review comments.

Edited by: R. Woods 